\title{
AS PESQUiSas QUALITATIVA E QUANTITATIVA COMO MÉTODOS DE INVESTIGAÇÃO CIENTÍFICA: UM ESTUDO COMPARATIVO E OBJETIVO
}

\author{
Sidney Proetti*
}

\section{RESUMO}

Este texto tem como objetivos apresentar, de forma simples e prática, os conceitos de pesquisa qualitativa e pesquisa quantitativa e esclarecer suas formas de uso nas pesquisas acadêmico-científicas. $O$ estudo foi fruto de uma pesquisa bibliográfica de longa profundidade, como revisão de obras de metodologia. É muito comum encontrar graduandos e pós-graduandos que têm dificuldades tanto no entendimento quanto na escolha correta do tipo de pesquisa que utilizará nas suas buscas de dados para a solução de problemas de pesquisa em trabalhos científicos. Ao longo deste texto, poder-se-á entender as definições de cada uma delas com a utilização de citações literais comentadas e, também, os seus elementos de diferenciação.

Palavras-chave: conhecimento científico; métodos; pesquisa qualitativa; pesquisa quantitativa.

\begin{abstract}
:
The purpose of this text is to present, in a simple and practical way, the concepts of qualitative research and quantitative research and to clarify their use in academic-scientific research. The study was the fruit of a deep bibliographical research, as a review of works of methodology. It is very common to find postgraduate students who have difficulties both in understanding and

\footnotetext{
* Doutor em Comunicação Social; Mestre em Administração; Mestre em Comunicação Social; Docente e Coordenador dos cursos de Ciências Contábeis e MBA em Gestão Estratégica de Negócios no Centro Universitário Assunção - UNIFAI; Professor da FAM - Faculdade das Américas. Foi professor na PUC-SP; Autor dos livros: Metodologia do Trabalho Científico: abordagens para a construção de trabalhos acadêmicos; Praticando a Metodologia do Trabalho Científico; Simplificando a Lógica; Introdução ao Marketing; Reflexões para Melhorar o Ambiente de Trabalho; A Evolução da Administração e a Motivação no Ambiente de Trabalho; Liderança Eficaz; Gestão Empresarial Eficaz; A (In)Formação do Líder Eficaz. Autor de vários artigos científicos em diversas áreas como sociologia, globalização, turismo, comunicação, gestão de negócios, qualidade e administração.
} 
in the correct choice of the type of research that will use in their data searches for the solution of research problems. Throughout this text, one can understand the definitions of each of them with the use of commented literal citations and also their elements of differentiation.

Keywords: scientific knowledge; methods; qualitative research; quantitative research.

\section{INTRODUÇÃO}

Os métodos qualitativos e quantitativos não se excluem, e contribuem para o entendimento e a quantificação dos aspectos lógicos e essenciais de um fato ou fenômeno estudado. São procedimentos de cunho racional, intuitivo e descritivo que auxiliam os pesquisadores em seus estudos científicos e profissionais.

As pesquisas qualitativa e quantitativa permitem a reflexão dos caminhos a serem seguidos nos estudos científicos, pois auxiliam para entender, desvendar, qualificar e quantificar de forma verificativa, bem como permitem estudar a importância dos fenômenos e fatos para que se possa mensurá-los.

Entender sobre a utilização dessas pesquisas (qualitativa e quantitativa) permite a escolha das metodologias e ferramentas de coletas e análise de dados e informações de modo correto, produtivo e eficaz, pois o conhecimento se constrói com estudos de forma planejada, pensada de modo racional.

A pesquisa qualitativa não visa à quantificação, mas sim ao direcionamento para o desenvolvimento de estudos que buscam respostas que possibilitam entender, descrever e interpretar fatos. Ela permite ao pesquisador manter contato direto e interativo com o objeto de estudo. A pesquisa quantitativa segue com rigor de estudo a um plano previamente estabelecido, com hipóteses e variáveis definidas pelo estudioso. Ela visa enumerar e medir eventos de forma objetiva e precisa.

Este texto nasceu em duas etapas: na primeira, buscaram-se, em um levantamento bibliográfico, informações conceituais e históricas sobre as pesquisas qualitativa e quantitativa que, segundo FACHIN, definem-se como: 
... o ato de ler, selecionar, fichar, organizar e arquivar tópicos de interesse para a pesquisa (...) é a base para as demais pesquisas e pode-se dizer que é uma constante na vida de quem se propõe estudar." (FACHIN, 2001, p. 125)

Proetti cita:

Pesquisa bibliográfica: nesta pesquisa, faz-se uso dos materiais já publicados, escritos ou gravados mecânica ou eletronicamente, que contenham informações de diversas áreas. (PROETTI, 2005, p. 94)

Pôde-se, então, entender a complexidade dos temas. Embora se tenha consultado autores diferentes, eles caminham, desenvolvem e discutem o assunto de forma a obter as mesmas ideias, conceitos, fundamentações e, principalmente, suas visões sobre essas formas de abordagens. Foram muitas horas de leitura de diversas obras e não se pôde perceber que os autores contemporâneos divergem ou demonstram preferências nas pesquisas, até por notar que seus livros são compilações, como diria Umberto Eco ${ }^{1}$. A segunda etapa foi desenvolvida em decorrência da apresentação de um seminário deste autor na disciplina de Metodologia Científica para o doutorado em Comunicação Social da Universidade Metodista de São Paulo. As reflexões desenvolvidas ao longo deste estudo foram fundamentais para que se pudesse entender, de forma mais profunda, as definições das pesquisas qualitativa e quantitativa, suas aplicações isoladamente ou, principalmente, de forma conjunta. A cada passo em que se estabeleciam os conceitos abordados pelos autores consultados e se desvendavam suas aplicações, pôde-se verificar e entender as diferenças, as complexidades e a importância do assunto em questão.

Ao longo deste texto serão abordadas as definições e efetuados esclarecimentos para que se possa entender a importância dessas pesquisas, assim como os caminhos trilhados por essas formas de estudo. No final do texto, poder-se-á observar as diferenças básicas, de forma comentada, desses tipos de pesquisas.

\footnotetext{
${ }^{1}$ Cf. Como se faz uma tese. 19. ed. São Paulo: Perspectiva, 2004, p. 3.
} 


\section{CONCEITOS: AS PESQUISAS QUALITATIVA E QUANTITATIVA}

É importante, antes de apresentar qualquer tipo de conceituação, ressaltar três aspectos que são essenciais para o entendimento do uso das pesquisas qualitativa e quantitativa. $\mathrm{O}$ primeiro é que as pesquisas qualitativa e quantitativa podem ser utilizadas, ao longo de um estudo científico, tanto de forma isolada quanto de forma conjugada, isto é, quando se empreendem esforços em pesquisas na busca de respostas, poder-se-ão utilizar ambas as formas de pesquisa, pois os objetivos e as necessidades metodológicas assim o exigirão para que sejam obtidos dados corretos no estudo. Basta a escolha indevida do tipo de pesquisa e dos métodos para se ter dificuldades no levantamento de dados e não se conseguir uma conclusão de pesquisa a contento ou adequada ao estudo que se pretende desenvolver.

Os conhecimentos científicos são obtidos por procedimentos metodológicos que permitem a busca, análise, interpretação e entendimento dos fatos e fenômenos que, em alguns casos, poderão ser observados, definidos, manipulados, experimentados, controlados, recompostos e entendidos. As pesquisas qualitativas e quantitativas contribuem para o desenvolvimento da ciência e o aumento do saber do homem. Mesmo que certas linhas de pensamento como, por exemplo, o Positivismo, tenham criticado a forma qualitativa de pesquisa, não se pode desprezá-la, pois algumas áreas das ciências, como a educação e a comunicação social, por exemplo, são fundamentais para o desenvolvimento científico e utilizam a pesquisa quantitativa para compreender os fatos. $\mathrm{O}$ questionamento e a desconfiança dos pesquisadores e das ciências exatas são naturais por serem quantitativos em suas explicações científicas, entretanto não se pode abrir mão de que o mundo precisa ser explicado de forma também racional e que nem todo fato poderá, às vezes, ser mensurado quantitativamente, como é o caso do comportamento individual de um ser humano. Após o entendimento do comportamento, poder-se-á identificar a frequência de suas atitudes e ter-se, nesse exemplo, o uso conjugado das pesquisas qualitativas e quantitativas. O importante é que os pesquisadores "abram suas mentes" e passem a ter uma visão mais global do mundo em que vivem e que entendam que, dependendo da complexidade dos estudos e dos objetivos a 
serem alcançados, os métodos e técnicas de pesquisa deverão ser escolhidos independentemente de dogmas, individualidades e linhas de pensamento egoístas.

Encerrada a exposição do primeiro aspecto, tem-se o segundo, que precisa ser explicitado: o conhecimento científico, assim como o filosófico, é racional e isso lhe confere a pretensão de revelar aspectos de realidade de forma sistemática, planejada e organizada. Segundo Odília Fachin, o conhecimento científico pode ser entendido e interpretado para a evolução das ciências, pois pressupõe uma aprendizagem superior:

\footnotetext{
O conhecimento científico pressupõe uma aprendizagem superior. Ele se caracteriza pela presença do acolhimento metódico e sistemático dos fatos e da realidade sensível. Por meio da classificação, da comparação, da aplicação dos métodos, da análise e síntese, o pesquisador extrai do contexto social, ou do universo, princípios e leis que estruturam um conhecimento rigorosamente válido e universal. $\mathrm{O}$ conhecimento científico preocupa-se com a abordagem sistemática dos fenômenos (objetos), tendo em vista seus termos relacionais que implicam noções básicas de causa e efeito. (FACHIN, 2001b, p. 11)
}

O terceiro aspecto a ser apresentado é exatamente o de lembrar que o termo pesquisa tem intrinsecamente a ideia de investigação com operações e trabalhos de forma intelectual e prática, busca de verdades, verificação com objetivos de descobertas de novos conhecimentos para serem utilizados pela sociedade como um todo. Essa visão é essencial e não pode, de modo algum, denotar sensacionalismo de forma egoísta. A ciência é o acúmulo do saber de forma universal e deve prestar contas e serviços à humanidade. A ciência está delineadamente ligada às universidades, com grandes interesses do restante da sociedade (principalmente a indústria). Máttar Neto assim a afirma:

A pesquisa, nas universidades, realiza-se principalmente em consonância com os cursos de pós-graduação, especialmente a pós-graduação Stricto Sensu, embora notemos suas mentes já nos cursos de graduação, com os projetos de iniciação científica... (MÁTTAR NETO, 2002, p. 95) 
Após a exposição dos três aspectos e o entendimento da importância de cada um deles para a formação de um raciocínio mais científico e adequado para a leitura analítica deste texto, poder-se-á, então, iniciar a apresentação dos conceitos das pesquisas qualitativa e quantitativa para que se obtenha uma melhor e mais adequada visão da importância dessas pesquisas.

Em consulta ao Dicionário de Filosofia, de Nicola Abbagnano ${ }^{2}$, encontraramse conceitos de qualidade e quantidade que se fazem necessários para entender, exatamente, as definições consideradas como raízes básicas dos termos utilizados como pesquisa qualitativa e quantitativa. Por qualidade e quantidade, a obra apresenta e destaca conceitos genéricos e também específicos citando, inclusive, definições de Aristóteles. Segundo ABBAGNANO, os termos qualidade, do latim Qualitas, e quantidade, do latim Quantitas, possuem os seguintes significados:

QUALIDADE (...) Qualquer determinação de um objeto (...). A noção de Q. é extensíssima e dificilmente pode ser reduzida a um conceito unitário. Podemos dizer que ela compreende uma família de conceitos que têm em comum a função puramente formal de servir de resposta à pergunta qual?... (ABBAGNANO, 1998, p. 816)

QUANTIDADE (...) Em geral, a possibilidade da medida. Foi esse o conceito emitido por Platão e Aristóteles. Platão afirmou que a Q. está entre o ilimitado e a unidade, e que só ela é o objeto do saber (...) Aristóteles, por sua vez, definiu a Q. como o que é divisível em partes determinadas ou determináveis. Uma Q. numerável é uma pluralidade divisível em partes descontínuas. Uma Q. mensurável é uma grandeza divisível em partes contínuas, em uma, duas ou três dimensões... (ABBAGNANO, 1998b, p. 816)

Percebe-se que o termo qualidade possui conotação de menor objetividade do que o termo quantidade. Neste contexto, pode-se entender uma diferença importante nas pesquisas qualitativa e quantitativa, pois, objetivamente, esta se preocupa em mensurar fatos divisíveis, assim como se pode exemplificar com a ciência da Física e da Matemática. Já aquela não se preocupa em enumerar, mas, sim, entender os fatos e fenômenos para explicálos. Nessa mesma linha de raciocínio, o filósofo Kant tratava da quantidade das proposições

\footnotetext{
${ }^{2}$ Obra publicada originalmente em italiano com o título Dizionario Di Filosofia por Unione Tipográfico-Editrice Torinense - UTET, Torino, 1971. Foi concedido Copyright à Livraria Martins Fontes Editora Ltda. em 1998 com tradução de Alfredo Bosi.
} 
e a reduzia a três classes de juízo, conforme cita ABBAGNANO (1998:819), como "proposições universais, particulares e individuais"; enquanto Aristóteles definia a quantidade em proposições universais e particulares e individuais e indefinidas.

Esses prenúncios ajudam a iniciar o entendimento sobre os objetivos das pesquisas qualitativa e quantitativa. Faz-se necessário, então, citar os conceitos definidos por outros autores que se dedicam ao estudo da Metodologia Científica para facilitar os caminhos da pesquisa. De forma clara e específica, Arilda Schmidt Godoy define essas pesquisas da seguinte forma:

\begin{abstract}
Em linhas gerais, num estudo quantitativo, o pesquisador conduz seu trabalho a partir de um plano estabelecido a priori (...). Preocupa-se com a medição objetiva e a quantificação dos resultados (...) a pesquisa qualitativa não procura enumerar e/ou medir os eventos estudados, nem emprega instrumental estatístico na análise dos dados. Parte de questões ou focos de interesses amplos, que vão se definindo à medida que o estudo se desenvolve. Envolve a obtenção de dados descritivos sobre pessoas, lugares e processos interativos pelo contato direto do pesquisador com a situação estudada, procurando compreender segundo a perspectiva dos sujeitos, ou seja, dos participantes da situação em estudo. (GODOY, 1995, p. 58)
\end{abstract}

Na citação acima, GODOY deixa claro que a pesquisa qualitativa pode ser utilizada para estudar fenômenos ou fatos que envolvem seres humanos nas suas relações sociais em seus diversos ambientes como, por exemplo, de trabalho profissional, acadêmico, familiar, associações de classe, religioso, etc. Isso remete ao pensamento de que, por essa perspectiva, poder-se-á entender um fato ou fenômeno social configurando a pesquisa qualitativa como facilitadora do entendimento dos fatos estudados cientificamente.

A pesquisa qualitativa é realizada normalmente no local de origem dos fatos (objetos de estudo) e tem por objetivo demonstrar os resultados pelo sentido lógico/coerente que eles apresentam, ou seja, o sentido lógico que resulta do tratamento científico empenhado pelo pesquisador. Esse tipo de pesquisa possibilita investigar os fatos e compreendê-los no contexto em que eles ocorreram ou ocorrem, pois o pesquisador vai a campo para levantamento e coleta de dados, analisa-os e pode entender a dinâmica dos fatos.

Outra argumentação interessante, que fundamenta a pesquisa qualitativa, está na visão de Pedro Demo que afirma, em sua obra, que a qualidade tem significados como essência designando que é a parte mais relevante e central das coisas e dos fatos, pois, apesar de ser um 
conceito vago, não é possível de ser tocada e nem vista. Demo também sinaliza que a qualidade tem significado de perfectibilidade, sobretudo dos seres humanos, também é sinônimo de participação e, finalmente, afirma que ela aponta a dimensão de intensidade admitindo que a qualidade possui dinâmica complexa que pode aparecer em traços como vivências profundas que tendem a ser passageiras ou criarem rotinas. ${ }^{3}$

Para aprofundar ainda mais o estudo comparativo entre as pesquisas qualitativa e quantitativa, consultou-se, além de um dicionário de filosofia, a obra do Prof. Dr. Fábio Appolinário, o qual afirma que essas pesquisas têm as seguintes definições:

\begin{abstract}
Pesquisa qualitativa
[qualitative reserch] I. Modalidade de pesquisa na qual os dados são coletados através de interações sociais (p. ex.: estudos etnográficos e pesquisas participantes) e analisados subjetivamente pelo pesquisador; ...” (APPOLINÁRIO, 2004, p. 155)

Pesquisa quantitativa

[quantitative research] I. Modalidade de pesquisa na qual variáveis predeterminadas são mensuradas e expressas numericamente. Os resultados também são analisados com o uso preponderante de métodos quantitativos (ex.: estatística); II. Modalidade de pesquisa que investiga fatos... (APPOLINÁRIO, 2004b, p. 155)
\end{abstract}

É interessante verificar que alguns autores consideram a pesquisa qualitativa como subjetiva. Vale ressaltar que o termo subjetividade remete à ideia de individualidade e particularidade e se refere à redução da existência do sujeito observado e, quando se trata de ciência, é essencial lembrar que ela procura entender os fatos pela sua importância à raça humana e às demais ciências. $\mathrm{O}$ conceito de subjetividade, nesse caso, poderá comprometer o espírito científico e o postulado científico que tem como essência a objetividade, a razão, a descoberta de causa e efeito e, principalmente, a busca da verdade.

Já a pesquisa quantitativa tem por objetivo demonstrar, de forma quantificada, a importância dos dados coletados em uma verificação. Ela é apropriada para medir opiniões, atitudes, preferências por marcas de produtos, estimar potencial ou volume de um negócio e, também, para medir o valor e a importância de segmentos de mercado (marketing). Essa pesquisa se fundamenta no princípio de que a ciência é meramente quantitativa, pois os

\footnotetext{
${ }^{3}$ DEMO, Pedro. Metodologia do conhecimento científico. São Paulo: Atlas, 2000, p. 148-149.
} 
estudiosos/cientistas acreditam na importância da demonstração de estudos de forma metódica e numérica. Trata-se de mensurar para comprovar medidas de forma precisa e confiável por análise estatística. Para melhor exemplificar as pesquisas quantitativa e qualitativa, é importante citar as observações do Prof. Antonio Raimundo dos Santos:

... Quantitativa é aquela pesquisa onde [SIC!] é importante a coleta e a análise quantificada dos dados, e, de cuja quantificação, resultados automaticamente apareçam. Qualitativa é aquela pesquisa cujos dados só fazem sentido através de um tratamento lógico secundário, feito pelo pesquisador... (SANTOS, 2000, p. 30)

Santos (2000) confirma o contexto idealizado e explicitado neste trabalho. Quando se refere à pesquisa qualitativa como fator de coleta e análise dos dados, confirma o que outros autores citam e apresentam em suas obras ${ }^{4}$. Isso também ocorre com sua definição de pesquisa quantitativa, em que afirma a importância da análise de um objeto de estudo para a quantificação da importância dos seus dados e a mensuração, de forma precisa, no estudo de um fato ou fenômeno. Não se nota, portanto, que esse autor as considera excludentes nem que devem ser utilizadas com reservas ou cuidados por se tratar de métodos inseguros, mas sim as determina como formas de pesquisa, coleta e tratamento de dados em verificações científicas.

\section{DUAS POSIÇÕES EPISTEMOLÓGICAS SOBRE AS PESQUISAS QUALITATIVA E QUANTITATIVA: POSITIVISMO E INTERPRETACIONISMO}

Faz-se necessário, neste momento, enfatizar duas posições fundamentais para melhor entender os pressupostos das pesquisas qualitativa e quantitativa.

Discute-se, desde as primeiras linhas deste texto, que as pesquisas qualitativa e quantitativa não são excludentes e podem ser usadas de forma complementar. A qualitativa abdica quase que totalmente das abordagens matemáticas quando se tenta entender um fato pelo tratamento que dá aos dados coletados quando se está em fase de análise racional, pois trabalha preferencialmente com palavras orais e escritas, sons, imagens e símbolos.

Em obra publicada em 2002, Moreira apresenta duas posições essenciais de caráter epistemológico e disserta que estudiosos e pesquisadores discutem diferenças e descréditos da pesquisa qualitativa em relação à quantitativa que criavam tensões e posturas opostas. Segundo esse autor, as diferenças de métodos de pesquisa causavam estas tensões:

\footnotetext{
${ }^{4}$ Vide as obras consultadas na bibliografia.
} 
... Existem, evidentemente, enormes diferenças de método entre a pesquisa qualitativa e a pesquisa quantitativa, seja esta experimental ou não. Mas essas diferenças de método ocultam diferenças epistemológicas mais profundas, isto é, visões diferentes sobre o papel da pesquisa empírica e sobre a própria natureza do ser humano.

De maneira simplificada, dentro das ciências sociais em geral, as tensões entre pesquisa qualitativa e quantitativa espelham as diferenças entre duas posturas opostas - ou quase isso - e que se têm confrontado há mais de cem anos e, de forma mais aguda, nas últimas décadas. Uma dessas posturas advoga que os métodos das ciências naturais devem ser transpostos, tanto quanto possível, ao estudo do homem; a outra postura, ao contrário, defende que as especificidades do ser humano praticamente exigem para seu estudo um conjunto metodológico diferente que leve em conta que o homem não é um organismo passivo, mas sim que interpreta continuamente o mundo em que vive... (MOREIRA, 2002, p. 44)

Analisando-se a citação acima, percebe-se que o autor enfatiza que a primeira postura remete ao Positivismo, pois leva diretamente a lembrar sobre os métodos quantitativos. Pesquisadores que adotam as orientações positivistas são, de forma geral, aqueles que aceitam o comportamento humano como resultante de forças, fatores e estruturas internas ou externas que agem sobre as pessoas para gerar determinados resultados, que podem ser mensuradas por métodos experimentais e levantamentos amostrais. Quando ele se refere à segunda abordagem, percebe-se que encaminha o estudo do homem aos métodos qualitativos que são chamados de forma genérica de Interpretacionismo.

As bases do Positivismo contemporâneo, fundamentadas por Auguste Comte (Curso de Filosofia 1830-1842) e John Stuart Mill (Sistema de Lógica 1843), defendem que as ciências humanas e sociais deveriam seguir os métodos lógicos das ciências físicas. Comte argumentava que o método científico provia os meios fundamentais tanto para o desenvolvimento da condição humana, como para o desenvolvimento das formas mais efetivas para lidar com essa condição. Na visão de Comte, a ciência era uma forma de emancipação da Teologia e da especulação metafísica.

Emile Durkheim foi outra grande influência do modelo científico de levantamento amostral, o qual contribuiu para que a própria análise quantitativa atual ficasse mais sofisticada devido ao advento do computador como ferramenta de análise estatística. De acordo com esses positivistas, a quantificação de variáveis ou dos fatores estudados é extremamente proveitosa, pois permite procedimentos estatísticos. Com o uso de dados vinculados a experimentos, levantamentos amostrais e outras práticas de contagem de dados, os positivistas se preocupavam com a descoberta e a especificação das estruturas do comportamento humano, em termos de variáveis dependentes e independentes para entender quantitativamente porque as pessoas agem desta ou de outra maneira.

Na visão dos interpretacionistas, as pessoas são diferentes dos objetos. Para estudá-las, são necessárias metodologias que interpretem essas diferenças, pois enxergam a vida das pessoas de forma dependente umas das outras. Os procedimentos adequados, segundo eles, 
são do tipo etnográfico, observação participante e entrevistas abertas. É nesse contexto que os quantitativistas criticam a pesquisa qualitativa como subjetiva em relação à pesquisa quantitativa.

\section{O PLANEJAMENTO DE PESQUISAS QUALITATIVAS}

O planejamento das pesquisas qualitativas não apresenta facilidade quando é estruturado, pois, por sua diversidade de aplicação e flexibilidade, até por ser menos objetiva em sua forma do que a pesquisa quantitativa, não admite regras precisas que poderiam ser aplicadas em uma gama de casos. Esse fato ocorre por não ser possível definir regras no projeto de pesquisa que tenham precisão, pois os fatos e objetos de estudos a serem verificados serão, algumas vezes, observados em seu pleno desenvolvimento. É lógico que para fatos já ocorridos, o planejamento torna-se mais fácil em termos metodológicos.

É importante ressaltar que, quanto menos experiência tiver um pesquisador, mais precisará de um planejamento cuidadoso, pois poderá se perder na quantidade excessiva de dados extraídos nos estudos de campo. Isso, então, prejudicará o entendimento do real significado dos dados. Nos estudos qualitativos, por exemplo, a coleta sistemática dos dados de pesquisa deve ser iniciada e precedida pela imersão do estudioso/pesquisador, sempre que possível, no contexto do fato a ser estudado. Esta é exatamente uma fase exploratória que permite um melhor planejamento do trabalho e devem ser definidas algumas questões iniciais para o bom desenvolvimento do estudo.

Um planejamento adequado, independentemente de ser estudo qualitativo, quantitativo ou de ambos, requer a priori a elaboração de um projeto de pesquisa com a orientação de professores experientes. A pesquisa bibliográfica, com leitura analítica, é de suma importância nas pesquisas qualitativas, pois sugerem conhecimentos prévios que servem de base para o entendimento do assunto e ajudam a entender os fatos analisados.

\section{CAMINHOS PARA A PESQUISA QUALITATIVA}

Como se pôde perceber, este texto está sendo trabalhado e construído de forma a comparar e identificar os aspectos principais desses tipos de pesquisas e apresentar seus objetivos. A partir deste momento, serão demonstrados três caminhos que auxiliam e conduzem as investigações científicas nos estudos qualitativos: a pesquisa documental, o estudo de caso e a etnografia. ${ }^{5}$

\footnotetext{
5 GODOY, Arilda Schmidt. Introdução à pesquisa qualitativa e suas possibilidades. RAE - Revista de Administração de Empresas. São Paulo. V. 35. n. 3. p. 21
} 


\subsection{A PESQUISA DOCUMENTAL}

Utiliza-se esse tipo de estudo quando se deseja verificar, por exemplo, fatos de empresas que deixaram de funcionar e questões relacionadas a pessoas que já morreram. Caso algum estudioso queira fazer uma pesquisa para verificar quais foram as primeiras indústrias que chegaram e se instalaram no famoso bairro do Ipiranga, em São Paulo, poderá realizá-la por meio do levantamento de documentos na Junta Comercial e na Associação Comercial do bairro. Esses documentos são, normalmente, jornais e revistas, diários, contratos sociais, cartas, relatórios e demais documentos que registraram a sociedade e a fundação das empresas naquela época.

É importante lembrar que os documentos arquivados em cartórios, associações comerciais e demais repartições públicas constituem-se como fontes não-reativas, pois as informações neles contidas permanecem as mesmas após longos períodos de tempo. Entretanto, cabe ressaltar que nem sempre os documentos antigos constituem amostras representativas dos fatos estudados. Eles poderão apresentar 'ilegibilidade' pelo tempo de existência ou, até, dúvidas em suas informações por não ser possível confirmar a autenticidade das informações neles registradas.

A pesquisa documental é feita pela análise do seu conteúdo e comporta três fases para que seja confiável como método de estudo. A primeira fase é denominada pré-análise e é identificada como fase de exploração do material com uma leitura atenta, porém rápida. Tratase de uma análise textual. Nessa fase, é importante traçar o planejamento para a pesquisa, as hipóteses e os objetivos a serem alcançados com o estudo. A segunda fase é a de exploração do material, que é exatamente o cumprimento da primeira fase de maneira determinada e progressiva. Nessa fase, retoma-se a leitura só que de forma mais profunda (análise temática, interpretativa) e se faz a problematização das informações constantes nos documentos que se traduz em reflexão do conteúdo. É uma etapa de contextualização e contemporização. Finalmente, a terceira fase é a de tratamento dos resultados e interpretação. Nessa fase, 
obtém-se o entendimento do conteúdo do documento e pode-se, então, tornar válidos os seus significados.

\subsection{O ESTUDO DE CASO}

O estudo de caso consiste em selecionar um objeto para estudo de forma aprofundada em seus aspectos característicos. Visa-se, com esse estudo, a buscar entendimento sobre as características de um objeto de forma científica, questionar sua origem, seu desenvolvimento e suas influências. Esse caso pode ser composto de fatos ou fenômenos que despertaram a atenção do pesquisador. É necessário que o pesquisador tenha sólida formação científica e nível intelectual elevado, tenha poder (capacidade) de análise para o tratamento dos dados com o objetivo de se obter informações e, também, poder de síntese para construir novos conhecimentos. Godoy (1995) conceitua o estudo de caso da seguinte maneira:

\footnotetext{
O estudo de caso se caracteriza como um tipo de pesquisa cujo objeto é uma unidade que se analisa profundamente. Visa ao exame detalhado de um ambiente, de um simples sujeito ou de uma situação em particular. Não deve ser confundido com o 'método do caso', que constitui uma estratégia de ensino amplamente divulgada no curso de Administração... (GODOY, 1995b, p. 25)
}

Godoy (1995) deixa claro que o estudo de caso, como método de pesquisa, tem como propósito fundamental analisar, de forma intensiva, uma unidade social como, por exemplo, uma empresa ou um departamento dela, um líder de opinião em uma sociedade, casos esses que despertam a atenção do pesquisador e merece o esforço de um estudo de forma detalhada. Nesse tipo de estudo, pode-se responder como e porque certos fatos ocorrem, pois o pesquisador terá possibilidades de interagir presencialmente com o ambiente de estudo. $\mathrm{O}$ estudo de caso não deve, apenas, ser visto pelo aspecto do caso estudado em si, mas deve iniciar de acordo com uma temática de interesse do pesquisador tendo em vista o problema/questão de estudo que o motivou e que ele acredita ser interessante para pesquisar em contribuição à Ciência. 
No estudo de caso, como método de pesquisa, é fundamental adotar como técnicas de pesquisa os enfoques exploratório e descritivo, mesmo quando se inicia o trabalho de forma teórica, pois o contato com o ambiente em que o fato ocorreu ou está ocorrendo permitirá ao pesquisador manter-se alerta aos novos elementos que podem ocorrer e que ele deverá observar para apreender dados, analisá-los, transformá-los em informações e teorizá-los. Um aspecto importante a ser observado pelo estudioso é o de que se pode encontrar uma multiplicidade de dimensões específicas ao fato que devem ser registradas ao longo do estudo para se entender a realidade contida no objeto de estudo. Esse momento é, exatamente, o que configura a pesquisa como elemento de produção de novos conhecimentos e para a construção e ampliação do saber científico ${ }^{6}$. Assim, é essencial que nesse tipo de pesquisa sejam relatadas (documentadas) as realidades do fato como suas características, contexto social, sua forma de desenvolvimento e funcionamento e consequências ao ambiente de que faz parte. Há a possibilidade de o estudo de caso envolver dois ou mais sujeitos como objeto de estudo como, por exemplo, duas instituições, dois personagens como líderes importantes em uma sociedade. Têm-se, nesse estudo, casos múltiplos em que o pesquisador poderá descrever suas particularidades, suas formas de funcionamento, e realizar comparações significativas que contribuam com a formação de um raciocínio de maneira inteligente e científica, que valha a pena o desenvolvimento do estudo e dos esforços necessários para isso.

Finalmente, é importante lembrar que a organização pessoal do pesquisador não é o único fator de sucesso em um estudo de caso. Ele deverá ter paciência e, principalmente, conhecimentos metodológicos para analisar de forma adequada o ambiente que é o objeto de estudo, além de uma análise de conteúdo dos documentos internos desse ambiente e, também, utilizar-se de instrumentos de coleta de dados como o questionário ou o formulário de pesquisa que o ajudarão nos levantamentos de dados para um estudo correto, produtivo e compensador no que se refere à prática de pesquisa e à construção do conhecimento científico. Essas ferramentas de coleta de dados são essenciais no estudo de caso, pois contribuem para registrar dados e informações fundamentais para o entendimento do ambiente estudado.

\footnotetext{
${ }^{6}$ O Prof. Dr. Isaac Epstein (UMESP) apresenta reflexão sobre o tema Ciência Básica, Ciência Aplicada e Tecnologia e afirma esse fato em Divulgação Científica: 96 Verbetes, ed. Pontes, 2002. p. 55.
} 


\subsection{A ETNOGRAFIA}

A etnografia é um método de estudo utilizado para descrever características de determinadas populações e é muito utilizada pela Antropologia e, também, pelas áreas da Educação, da Psicologia Social e pela Administração de empresas por estar diretamente ligada na gestão de pessoas e empreendimentos.

A professora Arilda Godoy (UNESP - Rio Claro) explica que a etnografia abrange a descrição de eventos que ocorrem na vida de um grupo social e enfoca especial atenção nas suas estruturas sociais em decorrência do comportamento das pessoas que formam esse grupo. Ela cita em seu artigo publicado na Revista de Administração de Empresas - RAE (Fundação Getúlio Vargas - São Paulo) o conceito de etnografia segundo a visão de FETTERMAN $^{7}$ como a "arte e a ciência de descrever uma cultura ou grupo" (GODOY: 28). A interpretação dos significados desse estudo, em decorrência da observação e verificação do comportamento social do grupo, resultará na pesquisa etnográfica, daí se tem a rotulação ou definição da etnografia considerada como a "ciência da descrição cultural" em que se estabelecem como cultura elementos válidos como, por exemplo, o conjunto de crenças, conhecimentos e ideias de um determinado grupo de pessoas que expressam determinado comportamento em um local de vida comum.

O entendimento do funcionamento de um grupo social, resultante da pesquisa etnográfica, é fruto de pesquisa qualitativa. Nesse tipo de estudo, o trabalho de campo é o elemento-chave para a obtenção de conhecimentos. É fundamental, nesse momento, ressaltar a complexidade da Metodologia do Trabalho Científico, pois seus métodos, tipos e técnicas de pesquisa se entrelaçam quando necessário para o estudo científico para a obtenção de novos conhecimentos. Não se trata, dessa forma, quando se fala ou se planeja a parte metodológica de uma pesquisa científica em um trabalho de conclusão de curso na graduação ou em dissertação ou tese de doutorado, de apenas escolher uma metodologia para mencionála no corpo textual desses trabalhos, mas sim na escolha dos métodos, das pesquisas e das técnicas adequadas para que se possa levantar e buscar dados de forma correta, sem correr

\footnotetext{
${ }^{7}$ FETTERMAN, D.M. Ethnography Step-by-Step. Newbury Park, CA: Sage Publications, 1980. p. 11
} 
riscos de cometer falhas, com o objetivo de descobrir novas verdades e de elaborar novas teorias científicas.

Após a exposição de forma explicativa dos tipos das pesquisas qualitativas e quantitativas que permitem e facilitam o caminho nos estudos científicos, faz-se necessário apresentar as diferenças entre elas em um quadro comparativo, para que seja possível entender as suas particularidades, campos de atuação, elementos básicos de análise do objeto de estudo, suas formas de interpretação de dados coletados, os tipos de raciocínios desenvolvidos e demais diferenças e elementos que as tornam métodos fundamentais de busca e de análise de dados. Poder-se-á obter uma visão mais clara de todos os aspectos dissertados no texto até aqui e entender os focos de trabalho desses dois tipos de pesquisas.

\section{A PESQUISA QUANTITATIVA NÃO-EXPERIMENTAL: O LEVANTAMENTO AMOSTRAL}

Após a apresentação de alguns caminhos para a pesquisa qualitativa, faz-se necessário manifestar uma breve visão da pesquisa quantitativa, de forma isolada, para contribuir com a formação do raciocínio lógico sobre esse tipo de abordagem científica.

É interessante observar que o próprio título, ou nome, desse tipo de pesquisa já é autoexplicativo: a pesquisa quantitativa não experimental afasta a hipótese do entendimento do conceito de pesquisa experimental. Essa ideia se fundamenta na possibilidade de manipulação de variáveis. A pesquisa não-experimental permite montar amostras com sujeitos que apresentam características variadas pela elaboração de listas, ou grupos de sujeitos escolhidos, também, de forma aleatória na qual se permite a possibilidade de participação total de um grupo no momento da escolha (sorteio). Nesse contexto não há manipulação, pois não é possível fraudar as variáveis, por exemplo, sexo, idade e estado civil. Os efeitos do estudo são a posteriori, pois serão medidos após a aplicação das entrevistas, por exemplo.

Para se efetuar uma análise na pesquisa quantitativa não-experimental, pode-se utilizar a análise de correlação, que consiste em correlacionar variáveis em pares correspondentes e submetê-las à análise estatística que indicará os valores de padrões considerados comuns entre 
os pares que apresentam variações dependentes. No contexto da pesquisa qualitativa nãoexperimental, o levantamento amostral permite a aplicação de questionários e escalas préestabelecidas com características e dados do objeto de estudo. Segundo Moreira, esse tipo de levantamento se define da seguinte forma:

\footnotetext{
"Um levantamento amostral é um procedimento sistemático para coletar informações que serão usadas para descrever, comparar ou explicar fatos, atitudes, crenças e comportamentos”. (MOREIRA, 2002b, p. 30)
}

O levantamento amostral admite etapas de estabelecimento de objetivos para que se possam coletar informações e analisá-las, de elaboração de um projeto de pesquisa de forma planejada, de preparação e aplicação de um instrumento de coleta de dados que seja válido, confiável e eficiente como, por exemplo, um questionário bem elaborado com perguntas lógicas, que permitam a obtenção de respostas precisas para que seja administrado e pontuado de forma sistemática e, finalmente, que permita, após a análise dos dados obtidos, informar os resultados ao público interessado no estudo.

O levantamento amostral permite medir atitudes no sentido de se perceber o interesse das pessoas em dada pesquisa, suas preferências quando se comparam objetos e suas crenças que de forma objetiva refletem seus comportamentos. $\mathrm{O}$ resultado desse estudo permite fazer previsões e mapear o futuro para possíveis decisões.

\section{AS DIFERENÇAS ENTRE AS PESQUISAS QUALITATIVA E QUANTITATIVA}

Pôde-se perceber, até aqui, que as pesquisas qualitativa e quantitativa não são excludentes, podem ou não ser utilizadas de forma independente e são essenciais quando se precisa entender e mensurar fatos. Elas oferecem recursos metodológicos com diferentes perspectivas para a realização de estudos, mas não são pólos opostos. Elas poderão ser utilizadas de forma complementar de acordo com o objeto a ser estudado e fornecer mais informações confiáveis para o pesquisador. A abordagem qualitativa apresenta-se, como se pôde observar nesse estudo comparativo, como a tentativa de compreender e explicar de 
forma detalhada os significados e as características situacionais dos objetos estudados. Ela realça valores, estuda crenças, representações culturais, opiniões e atitudes comportamentais de grupos de pessoas ou de casos e permite ao pesquisador a compreensão dos objetos estudados pelo alto grau de complexidade. As pesquisas quantitativas produzem a quantificação das características e da regularidade de ocorrência de um fato e atuam em níveis de realidade em que os dados são importantes e devem ser quantificados, pois indicam posições e ocorrências importantes para despertar a atenção de pesquisadores.

Alguns fatos poderão exigir o uso das pesquisas qualitativa e quantitativa, pois quando o fato permite e o objeto de estudo requer o entendimento e a quantificação de dados, elas devem ser utilizadas de forma complementar. Por isso, é difícil entender a não dependência dessas pesquisas em nenhum estudo. A visão de um pesquisador não pode ser medíocre a tal ponto, (ou talvez medíocre não seja o termo adequado para ser usado para referenciar cientistas e pesquisadores) que o impeça de se comportar cientificamente com imparcialidade, pois na atualidade deve-se pensar de forma ampla, irrestrita e neutra quando se realiza um estudo científico. Os métodos e técnicas devem ser utilizados de acordo com a necessidade do estudo em relação ao problema da pesquisa científica.

No quadro a seguir, poder-se-á observar as características individuais da pesquisa qualitativa e da pesquisa quantitativa. Essas características estão propostas de forma simples para facilitar a visão global das pesquisas qualitativa e quantitativa. Não são premissas inflexíveis e não denotam exclusividade individual, mas, sim, o ponto de vista obtido de acordo com os autores consultados que contribuíram para a formação do raciocínio do estudo bibliográfico para o desenvolvimento desse texto comparativo.

Quadro 1: As diferenças entre as pesquisas qualitativa e quantitativa.

\begin{tabular}{|l|l|}
\hline PESQUISA QUALITATIVA & PESQUISA QUANTITATIVA \\
\hline Menos objetiva. Não há acordo intersubjetivo. & $\begin{array}{l}\text { Objetiva (há acordo intersubjetivo - } \\
\text { convenções) }\end{array}$ \\
\hline Desenvolve Teorias & Testa teorias \\
\hline $\begin{array}{l}\text { Permite a percepção do fenômeno estudado e, } \\
\text { também, entender sua causalidade. }\end{array}$ & $\begin{array}{l}\text { Permite a percepção de forma quantificada do } \\
\text { fenômeno estudado. }\end{array}$ \\
\hline
\end{tabular}




\begin{tabular}{|c|c|}
\hline Permite selecionar e isolar casos. & $\begin{array}{l}\text { Permite selecionar população e amostras e } \\
\text { identificar suas propriedades. }\end{array}$ \\
\hline $\begin{array}{l}\text { O pesquisador pode observar as sequências, } \\
\text { os testemunhos com coletas de dados em } \\
\text { entrevistas para entender o contexto. }\end{array}$ & $\begin{array}{l}\text { O pesquisador consegue medir, correlacionar } \\
\text { e estabelecer estatísticas/escalas. }\end{array}$ \\
\hline $\begin{array}{l}\text { Possibilita a determinação de padrões, } \\
\text { selecioná-los e classificá-los. Nesse caso, é } \\
\text { possível entender a relação da pesquisa } \\
\text { qualitativa com a quantitativa. }\end{array}$ & $\begin{array}{l}\text { Compara os objetos de estudo e registra-os } \\
\text { quantitativamente por suas variações por } \\
\text { tabelas, quadros e relatórios quantitativos. }\end{array}$ \\
\hline $\begin{array}{l}\text { Descobre, compreende, descreve, interpreta e } \\
\text { partilha novos conhecimentos. }\end{array}$ & $\begin{array}{l}\text { Reduz (delimita) e controla os dados } \\
\text { (variáveis) e delimita-os de forma precisa. }\end{array}$ \\
\hline $\begin{array}{l}\text { Tem caráter organicista, pois o todo é mais do } \\
\text { que as partes e deve ser compreendido. }\end{array}$ & $\begin{array}{l}\text { É mecanicista. Os dados são iguais ao todo. } \\
\text { Comprova numericamente. }\end{array}$ \\
\hline $\begin{array}{l}\text { Possibilita e requer narrativas de forma } \\
\text { detalhada e interpretações um pouco mais } \\
\text { individuais para concluir pelo todo. Utiliza-se } \\
\text { do método indutivo. }\end{array}$ & $\begin{array}{l}\text { Utiliza-se do método dedutivo para conclusão } \\
\text { e aborda análises estatísticas. }\end{array}$ \\
\hline $\begin{array}{l}\text { Os elementos básicos para as análises são as } \\
\text { palavras, ideias e formam o raciocínio teórico } \\
\text { a que se pretende comprovar. Assemelha-se à } \\
\text { pesquisa participante. }\end{array}$ & $\begin{array}{l}\text { Os elementos básicos de dados para análises } \\
\text { são numéricos e expressam valores } \\
\text { conclusivos. }\end{array}$ \\
\hline $\begin{array}{l}\text { O pesquisador pode ou não participar do } \\
\text { processo e interagir com os atores sociais. No } \\
\text { caso de participação poderá vivenciar as } \\
\text { sensações do processo de pesquisa. A } \\
\text { anotação, a observação e o levantamento de } \\
\text { dados por meio de questionários, entrevistas e } \\
\text { formulários são essenciais para a obtenção de } \\
\text { informações. }\end{array}$ & $\begin{array}{l}\text { O pesquisador mantém distância do processo } \\
\text { de estudo (do objeto). }\end{array}$ \\
\hline $\begin{array}{l}\text { O resultado depende da análise do contexto } \\
\text { do fato (objeto estudado). }\end{array}$ & $\begin{array}{l}\text { Independe do contexto e registra o fato de } \\
\text { forma mensurada. }\end{array}$ \\
\hline $\begin{array}{l}\text { Formula problema de pesquisa e gera } \\
\text { hipóteses como respostas provisórias ao } \\
\text { problema. }\end{array}$ & Pode formular hipóteses e testá-las. \\
\hline $\begin{array}{l}\mathrm{O} \text { raciocínio desenvolvido no estudo é } \\
\text { dialético e/ou indutivo. }\end{array}$ & O raciocínio é lógico e dedutivo. \\
\hline
\end{tabular}




\begin{tabular}{|l|l|}
\hline $\begin{array}{l}\text { Descreve os significados das descobertas no } \\
\text { estudo. }\end{array}$ & Estabelece relações e causas do fato estudado. \\
\hline Busca particularidades no estudo. & Busca generalizações. \\
\hline $\begin{array}{l}\text { Preocupa-se com a qualidade das informações } \\
\text { e da conclusão do estudo para generalização. }\end{array}$ & $\begin{array}{l}\text { Preocupa-se com a importância nas } \\
\text { quantificações. }\end{array}$ \\
\hline Utiliza-se da comunicação e da observação. & $\begin{array}{l}\text { Utiliza-se de instrumentos específicos de } \\
\text { coleta de dados de forma numérica. }\end{array}$ \\
\hline
\end{tabular}

Fonte: autor.

$\mathrm{O}$ quadro $\mathrm{n}^{\circ} 1$ demonstra de forma objetiva e clara as diferenças entre as pesquisas qualitativa e quantitativa e chama a atenção, principalmente, em alguns (dois) aspectos: a forma de raciocínio desenvolvido e o tratamento dos dados em relação ao objeto de estudo. Percebeu-se que o raciocínio utilizado na pesquisa qualitativa pode ser dialético e/ou indutivo, o que leva a refletir sobre a importância da discussão na preparação do estudo, pois, na pesquisa qualitativa, pretende-se demonstrar a importância do todo por cada parte individual do objeto estudado. A ciência parte de princípios lógicos indutivos o que lhe confere um caráter de realidade dos fatos. Esse era o pensamento de $\mathrm{Hegel}^{8}$, que acreditava no pensamento que progride para uma síntese, com a busca contínua da resolução entre cada tese e sua antítese. Essa tese se desenvolve, pois, pelo que se percebeu neste estudo, a pesquisa qualitativa parte de princípios não mensuráveis que se baseiam em palavras escritas, orais, percepções obtidas por meio de imagens, sons, acontecimentos que demandam reflexão para serem entendidos. Mesmo que se trate de um estudo isoladamente qualitativo, não se perde o valor científico, pois o que importa é a contribuição às ciências em relação ao bem-estar do ser humano. Alves-Mazzotti e Gewandsznajder reforçam essa afirmação:

De qualquer forma, o fato de uma pesquisa se propor à compreensão de uma realidade específica, idiográfica, cujos significados são vinculados a um dado contexto, não a exime de contribuir para a produção do conhecimento. Seja qual for a questão focalizada, é essencial que o pesquisador adquira familiaridade com o estado do conhecimento sobre o tema para que possa propor questões significativas

\footnotetext{
${ }^{8}$ Jorge Guilherme Frederico Hegel, filósofo alemão que acreditava que "o racional é real, e o real é racional".
} 
e ainda não investigadas. (ALVES-MAZZOTTI \& GEWANDSZNAJDER, 2002, p. 151)

Já a pesquisa quantitativa trata os fatos desenvolvendo um raciocínio com a lógica dedutiva e estabelece as relações de causas dos fatos por testá-los matematicamente e estabelecer conclusões generalizadas. Nesse estudo são possíveis a quantificação e o tratamento estatístico do objeto de estudo.

Finalmente, é interessante entender que as duas formas de pesquisa são importantes e podem ser utilizadas de forma conjunta tanto para entender a importância de um fato pela sua origem, constituição e desenvolvimento, quanto para quantificar sua estrutura de constituição e seu desenvolvimento em relação ao tempo e projetar seu futuro para, se necessário, intervir em suas causas para novos acontecimentos. Isso justifica o uso da ciência em prol do ser humano. O quadro acima apresentado não deve ser entendido como um conjunto de estrutura única, entretanto, apresenta informações essenciais para o entendimento e para a compreensão dos objetos estudados como assuntos principais deste texto.

\section{CONSIDERAÇÕES FINAIS}

Procurou-se demonstrar neste artigo, os conceitos específicos e a importância das pesquisas qualitativas e quantitativas. É comum encontrar níveis diferentes de entendimento desses tipos de pesquisa, assim como, também, dúvidas entre os estudantes sobre a escolha delas de forma separada ou em conjunto para aplicação em campo. Essa dificuldade, aliás, permeia as mentes dos pesquisadores em formação, pois a ansiedade da busca de respostas aos problemas de pesquisa faz com que muitos iniciantes na pesquisa científica adotem questionários de forma imediata e se esqueçam de apresentar a metodologia adequada e específica para os estudos que desenvolvem em seu trabalho.

A pesquisa qualitativa, portanto, não pode ser considerada subjetiva como os positivistas a definiam. Ela é considerada menos objetiva por se tratar de estudo que visa a entender um fato. A pesquisa quantitativa poderá ser considerada objetiva, pois mensura e relata quantitativamente a importância de um objeto estudado. 
É importante deixar claro que se espera, após a leitura deste texto, a compreensão dos conceitos, usos metodológicos e das diferenças fundamentais entre essas pesquisas na coleta de dados e no tratamento deles. É importante relembrar conceitualmente que a pesquisa qualitativa visa a entender os fatos e fenômenos pelas suas dinâmicas e os trata de forma intelectual para poder descobrir suas origens, desenvolvimento, funcionamento, preocupandose em descrevê-los e explicá-los; enquanto a pesquisa quantitativa se preocupa em medir os fatos de forma a controlá-los e precisar quantitativamente sua existência. Esse enfoque foi intensamente enunciado neste trabalho.

Portanto, essas pesquisas não são as únicas a serem utilizadas em estudos científicos, entretanto, servem de base para o desenvolvimento deles e possibilitam agregar outros tipos de pesquisas para se conseguir a conclusão dos estudos com os respectivos esclarecimentos e mensuração dos objetos a serem estudados cientificamente. Elas contribuem com o crescimento da produção científica e permitem a construção do saber.

\section{REFERÊNCIAS BIBLIOGRÁFICAS}

ABBAGNANO, Nicola. Dicionário de filosofia (Trad. Alfredo Bosi). 2. ed. São Paulo: Martins Fontes, 1998.

ALVES-MAZZOTTI, Alda Judith; GEWANDSZNAJDER. O método nas ciências naturais e sociais: pesquisa quantitativa e qualitativa. 2. ed. São Paulo: Pioneira Thomson, 2002. 203 p.

CASSETARI, Leila; DOMENICO, Viviane Galhanone Cunha Di. Métodos e técnicas de pesquisa em psicologia: uma introdução. 3. ed. São Paulo: Edicon, 2002. 139 p.

DEMO, Pedro. Metodologia do conhecimento científico. São Paulo: Atlas, 2000. 216 p.

ECO, Humberto. Como se faz uma tese. Trad. Gilson Cesar Cardoso de Souza. 19. ed. São Paulo: Perspectiva, 2004.

EPSTEIN, Isaac. Divulgação científica: 96 verbetes. Campinas/SP: Pontes, 2002. 288 p.

FACHIN, Odília. Fundamentos de metodologia. 3. ed. São Paulo: Saraiva, 2001. 200 p. 
FETTERMAN, D.M. Ethnography Step-by-Step. Newbury Park, CA: Sage Publications, 1980. p. 11

GODOY, Arilda Schmidt. Introdução à pesquisa qualitativa e suas possibilidades. RAE Revista de Administração de Empresas. São Paulo. V. 35. n. 3. p. 21. 1995.

HÜBNER, Maria Martha. Guia para elaboração de monografias e projetos de dissertação de mestrado e doutorado. São Paulo: Pioneira-Mackenzie, 1999. 76 p.

MÁTTAR NETO, João Augusto. Metodologia científica na era da informática. São Paulo: Saraiva, 2002. 262 p.

MOREIRA, Daniel Augusto. O método fenomenológico na pesquisa. São Paulo: Pioneira, 2002. 152 p.

PROETTI, Sidney. Metodologia do trabalho científico: abordagens para a construção de trabalhos acadêmicos. 4. ed. São Paulo: Edicon, 2005. 126 p.

Praticando a metodologia do trabalho científico. 2. ed. São Paulo:

Edicon, 2005. 96 p.

RUIZ, João Álvaro. Metodologia científica. 4. ed. São Paulo: Atlas, 1996. 178 p.

SANTOS, Antonio Raimundo dos. Metodologia científica: a construção do conhecimento. 3. ed. Rio de Janeiro: DP\&A editora, 2000. 142 p.

TOBIAS, José Antonio. Como fazer sua pesquisa. 4. ed. São Paulo: AM edições, 1992. 71 p. 